\title{
'Sembur' culture:
}

\section{Local wisdom in care of pregnant mother with malaria in kupang}

\section{Budaya sembur: \\ Kearifan lokal dalam perawatan ibu hamil penderita malaria di Kupang}

\author{
Meiyeriance Kapitan ${ }^{1}$, Yuliana Dafroyati², Apryadno Jose Al Freadman Koa ${ }^{3}$ \\ ${ }^{1}$ Department of Nurse, Kupang Polytechnic of Health. Indonesia. \\ E-mail:edwardndoloe@gmail.com \\ 2Department of Nurse, Kupang Polytechnic of Health. Indonesia. \\ E-mail: yulianambedon@yahoo.com \\ 32Department of Nurse, STIKES Panakkukang Makassar. Indonesia. E-mail: apryadno@gmail.com
}

\begin{tabular}{|c|c|}
\hline ARTICLE INFO & ABSTRACT \\
\hline $\begin{array}{l}\text { Keywords: } \\
\text { Malaria; sembur culture; } \\
\text { pregnant mother; local } \\
\text { wisdom. } \\
\text { How to cite: } \\
\text { Kapitan, M., Dafroyati, Y., } \\
\text { Koa, A.J.A.F. (2020). } \\
\text { Budaya sembur: Kearifan } \\
\text { lokal dalam perawatan ibu } \\
\text { hamil penderita malaria di } \\
\text { Kupang. ETNOSIA: } \\
\text { Jurnal Etnografi } \\
\text { Indonesia. 5(1): } 150 \text { - } 163 . \\
\\
\text { DOI: } \\
\text { 10.31947/etnosia.v5i1.9344 }\end{array}$ & $\begin{array}{l}\text { Malaria is one of the main public health problems in the province of } \\
\text { East Nusa Tenggara (NTT). NTT currently ranks second in malaria } \\
\text { cases in Indonesia after Papua. Pregnant women are a risk group, data } \\
\text { show that pregnant women suffering from malaria complications in } \\
\text { Kupang District is still very high due to the delay in treatment since } \\
\text { many patients dominate the primary care of the traditional healer } \\
\text { compared to health services. The traditional healers use herbs that are } \\
\text { sprayed (sembur) to the patient. This action is an alternative } \\
\text { treatment carried out by the local community because it is far from } \\
\text { health facilities. Therefore, this study aims to determine the picture of } \\
\text { sembur culture in pregnant women suffering from malaria in Kupang } \\
\text { Regency. This study uses qualitative techniques with a } \\
\text { phenomenological approach. The informants were chosen by using } \\
\text { purposive sampling and snowball approach. There were six } \\
\text { informants, all of whom came from Kupang Regency. The data } \\
\text { collected through depth interviews and field notes. Processing and } \\
\text { analyzing data in the form of interview results are converted into } \\
\text { verbatim transcripts and the results of field notes are analysed in the } \\
\text { form of transcripts. The results of this study show three themes from } \\
\text { all participants; (1) health beliefs and practices; (2) thoughts and } \\
\text { feelings when conducting a sembur culture; (3) hope for a future life. } \\
\text { This research is beneficial for maternal and child health as well as } \\
\text { educational and service institutions. }\end{array}$ \\
\hline
\end{tabular}




\section{Pendahuluan}

Pasca usaha mempercepat pembangunan manusia yang biasa dikenal dengan Millenium Development Goals (MDGs) tahun 2015, dilanjutkan dengan Suistainable Development Goals (SDGs) atau tujuan pembangunan berkelanjutan di tahun 2015 - 2030, tujuan ke tiga dari tujuh belas tujuan adalah menjamin kehidupan yang sehat serta mendorong kesejahteraan bagi semua orang untuk semua kalangan usia (Hoelman et al., 2015). Hidup sehat untuk semua umur, termasuk bebas malaria. Malaria adalah salah satu masalah kesehatan masyarakat utama di provinsi Nusa Tenggara Timur (NTT). Menurut data dari Unicef ditemukan bahwa kasus malaria di NTT adalah 21\% dan menjadi yang tertinggi kedua di Indonesia setelah Papua, tetapi dalam jangka waktu sepuluh tahun, dari 2006 hingga 2015, kasus malaria di NTT menurun secara signifikan sebesar 71 \% (Unicef Kupang, 2016). Jumlah kasus malaria yang dikonfirmasi berjumlah 123.848 kasus menurun menjadi 36.128 pada tahun 2015, annual incidence of parasites (API) menurun dari 28,3 per 1.000 menjadi 7,1 per 1000 . API dalam kelompok risiko adalah 16 bayi per 1.000 dan 6 wanita hamil per 1.000 terutama data tentang ibu hamil belum dapat menggambarkan kondisi nyata karena skrining malaria di NTT masih rendah yaitu 47 persen ini menjadi salah satu tantangan kesehatan masyarakat terbesar dan memerlukan perhatian khusus dari pemerintah terutama kedua kelompok beresiko memiliki dampak buruk jika terinfeksi malaria.

Dampak negatif pada kesehatan ibu termasuk komplikasi selama kehamilan seperti anemia, anemia berat, demam, hipoglikemia, malaria serebral, infeksi plasenta, gangguan elektrolit, perdarahan postpartum, dan kematian (Suparman \& Suryawan, 2004) Ashley et al., 2006 Schantz-Dunn \& Nour, 2009 Okafor et al., 2012). Menurut Dunn dan Nour, 2009 yang dilakukan di Mozambik menemukan bahwa 25\% penyebab kematian ibu adalah infeksi malaria selama kehamilan. Janin yang terinfeksi malaria dapat menyebabkan aborsi, kelahiran prematur, lahir mati, pertumbuhan janin terhambat, kematian janin dalam kandungan/kematian janin Intra-Uterine, berat lahir rendah, malaria plasenta, dan kematian neonatal (kematian neonatal) (Suparman \& Suryawan, 2004; Ghana Health Service, 2009; Schantz-Dunn \& Nour, 2009; Olorunfemi E Amoran et al., 2012) juga didukung oleh penelitian Briand et al., 2007 menemukan bahwa dampak infeksi malaria selama kehamilan menyebabkan BBLR 8\% - 14\% dan kematian neonatal 3\% - $8 \%$. Komplikasi yang disebabkan oleh infeksi malaria pada wanita hamil dapat mempengaruhi peningkatan kematian bayi dan ibu.

Hasil Mass Blood Survey (MBS) tahun 2008, NTT sebagai provinsi yang memiliki kasus infeksi malaria terbanyak pada ibu hamil berjumlah 624 orang kemudian diikuti oleh provinsi Maluku sebanyak 455 orang. NTT memiliki 22 Kabupaten / Kota dan salah satunya adalah Kabupaten Kupang. Data prevalensi kasus malaria di Kabupaten Kupang sejak tahun 2015 hingga tahun 2017 memperlihatkan data meningkat yaitu 977 kasus tahun 2015, 1108 kasus tahun 2016 dan 5666 kasus pada tahun 2017 (BPS Provinsi NTT, 2018) apabila kita bandingkan hasil Riskesdas 2013 dan hasil Riskesdas 2018 di kabupaten Kupang memperlihatkan data penderita malaria yang melakukan pengobatan sendiri mengalami peningkatan dari 2,7\% menjadi 20,83\%(Badan Penelitian dan Pengembangan Kesehatan Kementerian Kesehatan RI, 2013) dan(Tim Riskesdas 2018 , 2019). Hal ini memperlihatkan bahwa salah satu penyebab meningkatnya kejadian 
malaria disebabkan oleh pengobatan yang tidak tepat sehingga seseorang yang telah terinfeksi malaria kemungkinan besar mengalami kekambuhan. Fakta di lapangan menunjukan banyak faktor yang mempengaruhi kegagalan pengobatan malaria selama kehamilan seperti tidak patuh dalam mengkonsumsi obat, resistensi obat malaria, dan terlambat melakukan kunjungan antenatal care (ANC) dilayanan fasilitas kesehatan masyarakat. Keterlambatan kunjungan ANC sesuai dengan hasil studi yang dilakukan oleh (Doku et al., 2016), keterlambatan melakukan kunjungan ANC memberikan dampak bagi ibu hamil yang merupakan kelompok risiko untuk tidak dilakukan deteksi dini. Keterlambatan melakukan deteksi dini malaria menimbulkan dampak yang luas bagi ibu dan janin.

Pengobatan malaria yang tidak tepat di Kabupaten Kupang dapat dipengaruhi oleh jarak rumah pasien dan kondisi geografis yang sulit dijangkau, karena terdiri dari daerah pegunungan, sungai dan transportasi yang sulit. Kondisi tersebut menyulitkan masyarakat untuk mendapat pelayanan kesehatan. Layanan kesehatan masih sering dilakukan oleh dukun atau pengobatan alternative lainnya. Pengobatan dengan bantuan dukun masih ada dan ini menjadi suatu kebiasaan oleh masyarakat setempat untuk mencari pengobatan alternative lainnya. Perilaku berobat adalah respon individu terhadap penyakit yang diderita, respon tersebut dapat berupa mendatangi rumah sakit, puskesmas, praktek dokter, atau tempat-tempat lain yang dianggap dan diyakini mampu membuatnya menjadi sehat. Menurut (Rosenstock, 1974) perilaku individu ditentukan oleh motif dan kepercayaannya, tanpa memperdulikan apakah motif dan kepercayaan tersebut sesuai atau tidak dengan realitas atau pandangan orang lain. Oleh karena itu, perilaku pencarian pengobatan oleh masyarakat dipengaruhi oleh jumlah dan jenis sarana pelayanan kesehatan yang tersedia di sekitarnya. Pada wilayah yang banyak tersedia sarana pelayanan kesehatan seperti puskesmas, rumah sakit pemerintah dan swasta, balai pengobatan serta praktek dokter, maka pilihan masyarakat semakin beragam untuk melakukan pencarian pengobatan (Gaol, 2013).

Perilaku berobat suku Timor dalam mencari pengobatan alternative seperti melakukan budaya sembur. Kata sembur sesuai dengan Kamus Besar Bahasa Indonesia diartikan sebagai apa yang dipancarkan (disemprotkan) dari mulut (seperti kunyahan obatobatan untuk mengobati orang sakit atau untuk mengusir roh jahat) (Kamus Besar Bahasa Indonesia, n.d.). Budaya sembur sering dilakukan oleh dukun atau seseorang yang diyakini mampu menyembuhkan penyakit seseorang. Bahan yang akan disembur berbentuk air yang sudah dicampur dengan ramuan tertentu, pilihan bahan yang disembur disesuaikan dengan kondisi kesehatan. Komposisi bahan semburan hanya diketahui oleh dukun yang menggunakan teknik menyembur. Tradisi ini telah lama dilakukan oleh masyarakat setempat dengan tujuan menghilangkan roh-roh jahat yang menyebabkan penyakit pada tubuh penderita. Masih ada masyarakat lokal yang yakin akan ritual tersebut meskipun sudah ada fasilitas kesehatan yang telah disiapkan oleh pemerintah (komunikasi pribadi dengan ketua lingkungan, petugas kesehatan di PKM Nule- Kabupaten Timor Tengah Selatan (TTS) dan PKM Tarus Kabupaten Kupang). Selain tradisi sembur, ada juga tradisi lain yang berasal dari suku Timor khususnya perawatan ibu melahirkan seperti Sei (dipanggang) dengan asap selama 40 hari. Tujuan Sei adalah agar tubuh ibu dan bayi selalu kuat (Soerachman, R dan Wiryawan, 2013). 
Beberapa hasil penelitian tentang malaria berhubungan dengan perilaku masyarakat seperti Penelitian kuantitatif yang dilakukan oleh Kapitan, (2013) di Sumba Barat Daya menunjukkan bahwa untuk meningkatkan kualitas pengetahuan dan perubahan perilaku responden maka responden tidak hanya mendapatkan informasi tentang malaria sebatas pemberian brosur maupun pemasangan spanduk saja, tetapi petugas kesehatan perlu memberikan informasi kesehatan tentang malaria dalam bentuk latihan dan di roleplaykan dalam kelompok - kelompok kecil sehingga pemahaman tentang malaria dapat dipahami dengan baik dengan memperlihatkan perubahan perilaku yang signifikan. Selanjutnya, penelitian kualitatif yang dilakukan oleh Dyah, (2012) menunjukkan bahwa pengalaman ibu hamil merawat diri ketika serangan malaria terjadi di Papua terbatas pada pengalaman ketika peserta menderita malaria tanpa komplikasi. Selanjutnya, Kapitan \& Ludji, (2019) dalam penelitiannya menunjukkan data wanita hamil dengan komplikasi malaria di kabupaten TTS lebih banyak melakukan perawatan dengan sembur oleh tua-tua adat setempat atau dukun tradisional sebelum dilakukan perawatan medis. Hasil penelitian membuktikan bahwa dampak malaria pada kehamilan cukup besar bagi kondisi ibu dan janin. Oleh sebab itu dibutuhkan tindakan segera untuk mengatasinya dan bekerja sama untuk semua lintas sektor.

Tradisi budaya sembur ini adalah salah satu kebiasaan pengobatan alternatif yang selalu dipertahankan oleh suku Timor. Suku Timor merupakan salah satu suku mayoritas di Kabupaten Kupang. Tradisi ini dijadikan pengetahuan lokal atau kearifan lokal masyarakat suku Timor di Kupang dalam merawat ibu hamil penderita malaria. Artikel ini akan menjelaskan 2 pokok hal, yaitu; (1) kearifan lokal terkait dengan medis dan non medis dalam pengobatan sembur bagi ibu hamil penderita malaria, (2) nilai-nilai yang dirasakan pada saat pasien atau perempuan hamil penderita malaria mendapatkan pelayanan kesehatan berbasis kearifan lokal, yakni budaya sembur.

\section{Metode}

Penelitian ini adalah penelitian kualitatif dengan fenomenologis yang berfokus pada topik yaitu gambaran budaya sembur yang dilakukan oleh penduduk setempat dalam merawat ibu hamil yang menderita malaria. Penelitian ini dilaksanakan di desa Noelbaki Kelurahan Tarus Kecamatan Kupang Tengah Kabupaten Kupang dengan pertimbangan dukun sembur banyak bermukim di lokasi tersebut dengan jumlah 4 orang yang tercatat dan dari 4 orang tersebut, ada 2 orang yang bekerja sebagai kader kesehatan berdasarkan informasi dari petugas PKM Tarus tahun 2017. Lokasi ini juga banyak ditemukan keluarga dengan latar belakang suku Timor, serta lokasi ini juga masih ditemukan adanya pengobatan dengan Dukun Sembur.

Penentuan informan penelitian diperoleh dengan cara purposive sampling dengan jumlah enam orang informan. Kriteria informan yang bergabung dalam penelitian ini adalah dukun yang memiliki pengalaman lebih dari 5 tahun dalam melakukan perawatan dengan menggunakan semburan. Daftar nama dan karakterisitk informan dalam penelitian ini dapat dilihat dalam tabel 1. Beberapa informan diperoleh dengan cara 
snowball karena beberapa informan tidak tercatat dalam data Pusat Kesehatan Masyarakat (PKM) setempat.

Tabel 1 Daftar Nama dan karakteristik Informan Penelitian

\begin{tabular}{cccclll}
\hline No & $\begin{array}{c}\text { Inisial } \\
\text { (Informan) }\end{array}$ & $\begin{array}{c}\text { Usia } \\
\text { (thn) }\end{array}$ & $\begin{array}{c}\text { Pendidikan } \\
\text { Terakhir }\end{array}$ & Pekerjaan Utama & Agama & Suku \\
\hline 1 & Tn. NA (I1) & 53 & SMP & $\begin{array}{l}\text { Ojek } \\
\text { konvensional }\end{array}$ & Kristen Protestan & Larantuka \\
\hline 2 & Tn. WB (I2) & 64 & SD & $\begin{array}{l}\text { Petani/Kader } \\
\text { Kesehatan }\end{array}$ & Kristen Protestan & Rote \\
\hline 3 & Tn. CN (I3) & 52 & SD & Kader Kesehatan & Kristen Protestan & Timor \\
\hline 4 & Tn. BK (I4) & 47 & SMP & Petani & Kristen Protestan & Sumba \\
\hline 5 & Tn. RK (I5) & 58 & SD & Petani & Kristen Protestan & Alor \\
\hline 6 & Tn. TRL (I6) & 80 & $\begin{array}{c}\text { Tidak } \\
\text { Besekolah }\end{array}$ & Gembala sapi & - & Sabu \\
\hline
\end{tabular}

Keterangan: SD (Sekolah Dasar), SMP (Sekolah Manengah Pertama)

Proses Pengumpulan data diawali dengan proses perizinan di Kantor Dinas Penanaman Modal dan Pelayanan Terpadu Satu Pintu (DPMPTSP) Provinsi Nusa Tenggara Timur (NTT) dan Layanan DPMPTSP Kabupaten Kupang. Setelah mendapat izin, peneliti melanjutkan perizinan ke Dinas Kesehatan Kabupaten Kupang dan lokasi PKM Tarus yang merupakan wilayah kerja dan terdapat data dukun sembur dengan jumlah yang cukup banyak untuk wilayah Kabupaten Kupang. Peneliti mengambil data sekunder dari lokasi Pusat Kesehatan Masyarakat (PKM) yang memiliki dukun terbanyak untuk melakukan praktek sembur. Tujuan dari pengambilan data sekunder ini adalah untuk mendapatkan nama informan dan alamat rumahnya. Selanjutnya peneliti menghubungi dan membuat kontrak dengan para informan untuk memulai proses pengumpulan data. Pengumpulan data dilakukan melalui wawancara mendalam (depth interview) ditambah dengan catatan lapangan (filed notes). Wawancara mendalam dilaksanakan untuk mendapatkan data gambaran (1) pengambilan keputusan masyarakat dalam memilih budaya sembur sebagai pengobatan malaria; (2) gambaran tentang pikiran dan perasaan dukun saat melakukan budaya sembur; (3) harapan kehidupan dukun tentang budaya sembur.

Analisis penelitian ini menggunakan tahapan bracketing, intuisi, analisis, dan menggambarkan penentuan peserta dalam penelitian ini. Penelitian ini memperhatikan pertimbangan etik dengan menjaga hak informan, menyeimbangkan antara keuntungan dan risiko dalam penelitian. Prinsip yang digunakan adalah informed consent, anonimity dan kerahasiaan.

\section{Hasil dan pembahasan}

\section{- Karakteristik Informan}

Dukun yang menjadi informan dalam penelitian ini sebanyak enam orang, yang merupakan praktisi pengobatan dalam bentuk budaya sembur di Kabupaten Kupang. Berikut karakteristik informan dalam penelitian ini:

Informan pertama adalah Tn. NA yang berusia 53 tahun, beragama Kristen, dari suku Larantuka. Memiliki pendidikan terakhir yakni sekolah menengah pertama (SMP), bekerja sebagai tukang ojek motor konvensional, memiliki penghasilan 1.000 .000 rupiah 
per bulan serta memiliki pengalaman sebagai dukun selama 30 tahun. Paerisipant tersebut juga bekerja sebagai kader khusus untuk pengobatan TB paru di Pusat Kesehatan Masyarakat Tarus. Menurut I1 ketika dia akan melakukan perawatan sembur pada pasiennya, dia selalu merekomendasikan pasien untuk terlebih dahulu melakukan pemeriksaan atau perawatan di fasilitas layanan kesehatan seperti pusat kesehatan, rumah sakit ataupun klinik. Jika perawatan ke layanan kesehatan tidak memuaskan atau dengan kata lain belum sembuh, maka ia menerima pasien untuk dirawat. Media yang digunakan sebagai bahan dasar penyemburan adalah tanaman dan kulit kayu seperti kumis kucing untuk ginjal, pinang, kayu, jahe, cengkeh, jarak, kayu hemoi dan garam. Lamanya proses yang dibutuhkan dalam perawatan tergantung pada keparahan atau penyakit yang diderita oleh penderita.

Informan kedua yaitu Tn. WB, berusia 64 tahun, beragama Kristen, dari suku Rote. Tingkat Pendidikan terakhir yakni sekolah dasar (SD), bekerja sebagai petani dan kader kesehatan, memiliki penghasilan 2.000.000 rupiah per bulan serta memiliki pengalaman sebagai dukun selama 22 tahun. Informan menangani pasien yang menderita kanker. Media yang digunakan adalah air, minyak kelapa, bunga trompet, sirih, dan kapur putih serta akan membacakan mantra - mantra khusus ketika melakukan pengobatan. Sebelum dilakukan pengobatan, pasien diminta untuk menyiapkan ayam merah untuk disembelih sebagai persaratan dalam proses pengobatan.

Informan ketiga yaitu Tn. CN, berusia 52 tahun, beragama Kristen, berasal dari pulau Timor. Pendidikan terakhir sekolah dasar, melakukan pekerjaan sambilan untuk memenuhi kebutuhan keluarga dengan penghasilan rata-rata 1.500 .000 rupiah per bulan serta memiliki pengalaman sebagai dukun selama 22 tahun. Peserta memiliki kemampuan untuk mengobati penyakitnya disebabkan oleh pengaruh kekuatan gelap. Sehari-hari bekerja sebagai kader kesehatan untuk PKM Tarus.

Informan keempat Tn. BK, berusia 47 tahun, beragama Kristen Protestan, berasal dari suku Sumba. Memiliki jenjang Pendidikan terakhir SMP, bekerja sebagai petani untuk memenuhi kebutuhan keluarga, memiliki pendapatan 1.250 .000 perbulan. Memiliki pengalaman sebagai dukun sembur selama 23 tahun. Informan dalam kesehariannya menjadi dukun untuk mengobati semua penyakit. Bahan yang digunakan adalah daun dan akar-akar tumbuhan tertentu yang berasal dari kampung halamannya di Sumba Timur. Bahan sembur yang digunakan tidak ditemukan di wilayah pulau Timor sehingga perlu didatangkan dari Sumba Timur.

Informan kelima yaitu Tn. RK, berusia 58 tahun, beragama Kristen Protestan, berasal dari suku Alor. Memiliki jenjang Pendidikan SD, bekerja sebagai petani untuk memenuhi kebutuhan keluarga, memiliki pendapatan rata-rata 850.000 perbulan. Memiliki pengalaman sebagai dukun sembur selama 27 tahun. Informan dalam kesehariannya menjadi tukang sembur untuk mengobati semua jenis penyakit. Bahan yang digunakan adalah air putih serta mantra khusus dalam pengobatan.

Informan keenam adalah Tn TRL, yang sudah berusia 80 tahun tidak memiliki agama, asal suku Sabu. Tidak tamat SD, bekerja sebagai penggembala sapi untuk memenuhi kebutuhan ekonomi keluarga, memiliki pendapatan rata-rata 1.000 .000 perbulan. Memiliki pengalaman sebagai dukun sembur selama 40 tahun. Informan dalam 
kesehariannya menjadi tukang sembur untuk semua jenis penyakit. Dalam kurun waktu 5 tahun terakhir ini, informan tidak lagi menerima pelayanan pengobatan sembur untuk orang pada umumnya, Ia hanya mengobati khusus untuk keluarga yang sakit. Informan keenam memiliki pengalaman yang buruk ketika mengobati orang dengan penyakit tertentu, pasiennya tidak berlaku jujur sehingga penyakit yang diderita oleh pasien tersebut ditularkan ke I6.

Keenam informan yang turut serta dalam penelitian ini, selain karakteristik yang berbeda, namun ada dua kesamaan yang dimiliki oleh ke enam orang informan tersebut, yaitu (1) Keenam informan berjenis kelamin laki-laki dan (2) memiliki kkemampuan untuk mengobati kliennya dengan menggunakan semburan yang dicampurkan dengan beberapa ramuan yang didapatkan dari alam, ilmu mengobati yang dimiliki merupakan hasil warisan dari leluhurnya. Hal ini memperlihatkan bahwa kemampuan ilmu seorang dukun sembur dalam pengobatan merupakan hasil warisan turun temurun. Obat yang dimiliki oleh masing-masing dukun tergantung dari hasil pembelajaran yang diwariskan dari dalam keluarga. Hal ini terlihat dari perbedaan bahan yang digunakan oleh masing-masing dukun ketika melakukan pengobatan.

Hampir semua informan yang ikut dalam penelitian ini memiliki tingkat Pendidikan yang rendah yaitu SD dan SMP bahkan ada salah satu informan yang tidak menyelesaikan sekolah dasarnya, kondisi ini memungkinkan bahwa latar belakang pendidikan formal yang dimiliki masih tergolong rendah sehingga menyebabkan kemampuan berpikir ilmiah dan rasional tidak diperhatikan atau di utamakan. Kondisi ini sesuai dengan teori Transcultural Leiningier (1985) dalam Leiningier \& McFarland, 2002 yang menyatakan bahwa semakin tinggi pendidikan formal seseorang maka dalam hal kemampuan menganalisis suatu masalah lebih baik yakni di fokuskan pada bukti bukti ilmiah yang rasional. Namun dalam penelitian ini didapatkan pula ada informan yang tetap memprioritaskan pengobatan medis terlebih dahulu sebelum dilakukan pengobatan tradisional dengan menggunakan metode sembur. Hal ini sesuai dengan peryataan dari salah satu informan yang menyatakan: "apabila ada pasien yang datang pengobatan namun masih ada pengobatan medis, saya tetap anjurkan untuk mengikuti pengobatan medis terlebih dahulu. (Wawancara NA).

Upaya seseorang untuk mendapatkan kesehatan merupakan suatu pranata khusus yang terus dipelihara dan dikembangkan pada masa primitif, pemahaman dan kepercayaan tentang kesehatan dipengaruhi budaya dan peradaban primitif pula (Foster \& Anderson, 1986). Budaya manusia tentang kesehatan juga berkembang, lebih lanjut dijelaskan Foster dan Anderson bahwa pemahaman masyarakat tentang kesehatan berpengaruh terhadap tindakan yang dilakukannya. Tingkah laku manusia dalam menghadapi masalah kesehatan bukanlah suatu tingkah laku yang acak (random behaviour), tetapi suatu tingkah laku yang selektif, terencana, dan terpola dalam suatu sistem kesehatan yang merupakan bagian integral dari budaya masyarakat yang bersangkutan. Tingkah laku yang selektif tersebut merupakan suatu strategi adaptasi sosial- budaya yang timbul sebagai respon terhadap ancaman penyakit. 
Perilaku tersebut terpola dalam pranata sosial dan tradisi budaya yang ditujukan untuk meningkatkan kesehatan.

\section{- Kepercayaan dan praktek kesehatan budaya sembur}

Ada beberapa prakek penyembuhan yang berada di kabupaten Kupang, baik penyembuhan medis maupun non medis, kedua macam penyembuhan tersebut yang dimnafaatkan oleh masyarakat setempat untuk menyembuhakan penyakit atau keluhan yang diderita. Penyembuhan yang dimaksud adalah dengan bantuan dukun atau yang bisa disebut di masyarakat adalah orang pintar. Kepercayaan dan praktek kesehatan yang dilakukan oleh para informan ketika melakukan budaya sembur sebagai pengobatan alternatif pada penderita sakit malaria ataupun penyakit jenis lainnya.

Ketika ditelusuri mengenai sumber pengetahuan budaya sembur, ternyata mereka mendapatkanya dari turun temurun. Empat orang informan menyatakan sejak jaman dahulu sebelum adanya pelayanan dari para medis, orang tua mereka melakukan pengobatan pada para para dukun sembur yang ada di sekitar wilayah kampung halaman mereka. Seperti yang disampaikan berdasarkan verbatim berikut:

"Kami orang Timor, Rote, Sabu dan Flores dari jaman dulu, kalo sakit org tua panggil bai bai yang biasa sumbur untuk pengobatan" (Wawancara NA; BK; RK).

"Percaya tidak percaya, sumbur ini paling cepat bikin orang sehat. Apalai kalo langar salah orang punya obat, sumbur cepat sembuh" (Wawancara NA dan WB).

Bahkan dua orang informan menyatakan bahwa pengobatan seperti penyakit batukbatuk jangka panjang dapat di obati dengan cara sembur.

Perilaku masyarakat dipengaruhi oleh kepercayaan masyarakat terhadap kesehatan. Model kepercayaan kesehatan (The Health Belife Model) menjadi dasar dalam perilaku masyarakat ini, dengan variabel-variabel pada kerangka teorinya yakni presepsi terhadap kerentangan, presepsi terhadap kerisauan sakit, presepsi terhadap manfaat dan rintangan-rintangan serta isyarat atau tanda-tanda pendorong (Young, 1980) yakni model perilaku terkait dengan pemilihan pengobatan dimana adaptasi lintas budaya yang terdapat pada model health belive atau model kepercayaan kesehatan yang meliputi empat unsur yakni gaya tarik atau gravity, pengetahuan tentang cara-cara pengobatan popular, kepercayaan, dan kemudahan. Berdasarkan konsep diatas yang diawali dengan takaran pemikiran setiap individu, disukung oleh kepercayaan dengan melihat jenis penyakit dan penyebab dari timbulnya penyakit yang dirasakan pada akhirnya akan mengarah pada pemilihan penyembuhan yang tepat dan sesuai.

Hampir semua informan menyatakan bahwa kebiasaan sembur yang dilakukan saat merawat orang sakit merupakan pengobatan yang paling bagus. Ketimbang harus pengobatan di dokter. Seperti yang disampaikan berdasarkan informan berikut:

"Sumbur obat paling mujarab, orang tua yang bilang. Sebelum ada dokter, pengobatan ini paling cepat. Bayangkan hanya dengan 2-3 kali sumbur, semua sakit hilang" (Wawancara NA; CB; BK; TRL).

Kepercayaan dan praktek perawatan orang sakit yang diwariskan oleh leluhur secara turun temurun dari beberapa etnis yang ada di Pulau Timor. Hal ini sesuai dengan rumusan dari konsep budaya menurut Koentjaraningrat, 2000 yang berasal dari Bahasa 
sansekerta "buddhayah" yang artinya akal. Defenisi budaya sebagai daya budi yang berupa cipta rasa, karsa dan rasa sedangkan kebudayaan adalah hasil dari cipta, karsa dan rasa itu. Tiga wujud dari kebudayaan adalah (1) wujud kebudayaan sebagai sebuah kompleks dari ide-ide, gagasan, nilai-nilai, norma-norma peraturan dan sebagainya. (2) wujud kebudayaan sebagai suatu kompleks aktivitas serta tindakan berpola dari manusia dalam masyarakat, (3) wujud kebudayaan sebagai benda-benda hasil karya manusia. Menurut Liliweri, 2002, kebudayaan merupakan pandangan hidup dari sekelompok orang dalam bentuk perilaku, kepercayaan, nilai dan symbol-symbol yang mereka terima tanpa sadar semuanya diwariskan melalui proses komunikasi dari satu generasi ke generasi berikutnya.

Dalam sistem kepercayaan sehubungan dengan penyembuhan penyakit, peranan dukun menjadi penting. Menjadi penyembuh dapat diperoleh melalui belajar dan keturunan (Geertz, 1981). Dukun bukan merupakan hal yang baru, karena dukun telah menjadi salah satu alternatif yang menjadi pilihan dalam penyembuhan beberapa penyakit bagi masyarakat Jeru. Istilah dukun berbeda-beda antara satu daerah dengan daerah lain, pada masyarakat Bugis dan Makassar, orang yang ahli mengobati penyakit secara tradisional dipanggil sanro, yang juga berarti dukun (Said M B, 1996).

Masih banyak masyarakat yang memilih pengobatan alternatif atau tradisional sebagai langkah untuk menyembuhkan penyakitnya, di samping menggunakan penyembuhan medis. Keberadaan dukun juga masih berguna bagi masyarakat sekitar. Bentuk kesehatan alternate (alternatif) dapat memenuhi kebutuhan kesehatan dari segi sosial, psikologi, dan mungkin pula organik, yang bagi beberapa orang tidak berhasil diperolehnya dari dokter maupun dari pelayanan kesehatan yang berkaitan. Dukun memiliki kemampuan tersendiri untuk menyembuhkan pasiennya, yang menggunakan metode yang berbeda dari metode yang digunakan oleh dokter.

Keyakinan yang ditanamkan oleh leluhur maupun orang tua mereka sangat kuat bagi individu pelaku sembur. Keyakinan inilah yang membantu para pelaku sembur sehinga dapat menjalankan kebiasaan pengobatan dengan menggunakan teknik serta tahapan tahapan pengobatan sembur. Hal ini sesuai dengan pernyataan Hawkins, 2012 yang menyimpulkan bahwa kebudayaan meliputi pengetahuan, keyakinan, seni, moral, adat istiadat serta kemampuan dan kebiasaan lain yang dimiliki manusia sebagai bagian masyarakat. Manusia sebagai mahkluk sosial budaya dipelajari dalam antropologi budaya yaitu tentang cara hidup manusia, bagaimana manusia dengan akal budinya dan struktur fisiknya dapat mengubah lingkungan berdasarkan pengalamannya. Kebudayaan manusia menganalisis masalah-masalah hidup sosial kebudayaan dan memberi wawasan bahwa manusialah yang mampu berkebudayaan. Sedangkan menurut Ralph Linton seperti yang dikutib dari Soekanto \& Sulistyowati, 2012 menyatakan bahwa budaya adalah segala pengetahuan, pola pikir, perilaku, ataupun sikap yang menjadi kebiasaan masyarakat dimana hal tersebut dimiliki serta diwariskan oleh para nenek moyang secara turun-temurun.

Budaya sembur yang dilakukan oleh informan tidak saja di gunakan oleh suku Timor tetapi ada beberapa suku yang meyakini akan khasiat pengobatan tersebut. Hal ini sesuai dengan pernyataan Rospand, 2008 menjelaskan bahwa istilah kultur jangan dirancukan dengan istilah ras. Ras mencirikan keturunan keluarga dan biologis yang 
sama. Namun kondisi ini lebih tepatnya di katakan sebagai keetnisan yaitu sekelompok individu yang dibangun secara sosial, kultural, dan politis yang memegang set karakteristik bersama yang tidak dibagi dengan orang lain, yang dengannya anggota membuat persetujuan.

Seiring dengan hasil penelitian yang dilakukan oleh Kadir, 2018 dalam risetnya di Mamuju memperlihatkan fakta adanya sector perawatan yang menggunakan dukun dimana pelaksananya adalah individu yang memiliki kemampuan yang bersifat sakral (sacred) maupun sekuler (secular) atau profane atau gabungan diantara keduanya, para dukun dikenal sebagai sando dan tomanarang. Sementara para dukun di kabupaten Kupang biasa dikenal sebagai "orang pintar". Sejalan dengan hasil penelitian Kadir, 2018 memperlihatkan adanya informan yang ketika terifeksi malaria lebih memilih mengobati sendiri tidak ke pusat layanan kesehatan terdekat.

Masih banyaknya pemahaman masyarakat yang ingin cepat sembuh tanpa mengeluarkan dana dan tenaga yang berlebihan sementara pengobatan di pelayanan kesehatan membutuhkan ekstra waktu, tenaga, biaya dan penyembuhan juga tidak serta merta sekali pengobatan langsung sembuh. Hal ini yang menyebabkan masih banyaknya masyarakat yang mencari pengobatan yang tidak rasional. Hal ini membutuhkan peran perawat dalam memberikan edukasi yang benar terkait pengobatan yang tepat dan juga perlu memahami masyarakat dengan budaya setempat.

Peran perawat sesuai dengan teori transcultural maka ketika melihat kondisi kelompok etnis yang masih menyelenggarakan ritual prosedur sembur dalam mencari kesembuhan untuk anggota keluarga yang sakit sebaiknya menerapkan culture care repatterning/restructuring. Menurut Leiningier \& McFarland, 2002 prinsip diatas merupakan prinsip rekonstruksi atau mengubah desain untuk memperbaiki kondisi kesehatan dan pola hidup klien ke arah yang lebih baik. Tujuan dari dilakukan prinsip ini untuk mencegah praktek pengobatan yang tidak rasional bisa saja menimbulkan kondisi kesehatan yang makin parah. Perawat maternitas juga perlu mensosialisasikan kepada masyarakat yang tidak mampu untuk mendapatkan perawatan dan pengobatan gratis, karena pemerintah Indonesia telah menyiapkan Kartu Indonesia Sehat (KIS) yang sangat baik untuk masyarakat miskin. Perlu diperhatikan bahwa dampak budaya sembur yang masih dilakukan hingga saat ini dipengaruhi oleh faktor ekonomi, hampir semua pengguna budaya sembur berasal dari keluarga yang memiliki latar belakang ekonomi tidak mampu.

Kebijakan penggunaan kartu KIS tidak hanya di pusat perkotaan, namun berlaku hingga daerah Kabupaten Kupang seperti yang ditemukan dalam studi ini bahwa semua masyarakat penderita malaria komplikasi maupun tidak komplikasi di Kabupaten Kupang mendapat pengobatan gratis sesuai dengan program kesehatan yang ada bagi masyarakat tidak mampu. Dukungan pemerintah telah banyak membantu peningkatan kesehatan seperti pemberian kartu jamkesmas dan jampersal sehingga memberikan dampak positif bagi pertumbuhan kesehatan masyarakat. Perubahan pertumbuhan kesehatan masyarakat tergantung juga pada motivasi serta harapan untuk dapat menjadi masyarakat Indonesia yang berkualitas baik yaitu adanya perubahan dalam pendidikan, kesehatan dan ekonomi. 


\section{- Nilai-nilai yang dirasakan saat pasien menjalani budaya sembur}

Pikiran dan perasaaan yang dirasakan oleh informan ketika melakukan pengobatan dengan sembur pada pasiennya dapat diuraikan dalam uraian dari kategori - kategori sebagai berikut:

a. Patuh pada kebiasaan leluhur

Hampir semua informan mengatakan budaya sembur merupakan kebiasaan orang tua, jadi sebaiknya dilakukan apabila ada yang datang meminta pertolongan untuk diobati. Seperti yang disampaikan dalam verbatim sebagai berikut:

"Beta menjalankan kebiasaan yang orang tua sudah buat selama berpuluh puluh tahun' (Wawancara WB; RK; TRL).

"Saya orang Timor jadi harus menjalankan kebiasaan yang dilakukan oleh leluhur saya" (Wawancara CN).

b. Membantu sesama manusia tanpa pamrih

Terdapat tiga orang informan yang mengatakan perasaannya ketika melakukan pengobatan dengan sembur, semata -mata hanya untuk membantu orang bisa terbebas dari penyakit, seperti yang di jelaskan dalam verbatim berikut:

"Tiap kali ada yang sakit malaria, ginjal, kanker, paru-paru mereka memanggil saya dengan tujuan sembur menggunakan ludah sirih pinang, kapur sirih atau daun/ kulit tanaman obat semburnya di bagian tubuh yang sakit" (Wawancara NA; WB; BK).

"Sembur pake air bersih saja, tapi kalo panas, menggigil, saya pake daun jarak putih dan halia, saya tidak minta bayaran" (Wawancara TRL).

"Tidak perlu pake uang, kalo niat membantu ya bantu saja" (Wawancara NA).

Sejalan dengan hasil riset yang dilakukan oleh Rospand, 2008 terhadap warga Amerika dalam kemiskinan memberikan prioritas yang tinggi untuk pemenuhan kebutuhankebutuhan dasar hidup sehari-hari (misalnya: makanan, tempat berteduh) dibanding peningkatan kesehatan dan pencegahan penyakit. Walaupun setiap individu dapat menderita kemiskinan, etnis minoritas cenderung lebih sering menjadi anggota kelompok kultural ini. Individu-individu dari status sosioekonomi yang rendah seringkali mencari pertolongan medis hanya setelah kondisi kesehatan mereka mengganggu kemampuan mereka bekerja. “Siklus kemiskinan” berkontribusi terhadap buruknya kesehatan yang terus menerus yang dialami oleh individu-individu yang kurang beruntung tersebut. Dalam siklus ini, individu tersebut tinggal pada lingkungan yang dapat menyebabkan buruknya perkembangan fisik dan intelektual, demikian juga buruknya produktivitas ekonomi, dan yang mengakibatkan, buruknya nutrisi. Hal ini mengarah pada peningkatan kesakitan dan penurunan lebih lanjut dalam produktivitas. 
Pada gilirannya, semua persoalan mengarah kepada tingkat morbiditas dan kecelakaan yang lebih tinggi, yang meningkatkan biaya asuhan kesehatan.

Hal ini sesuai dengan kondisi nyata di lapangan bahwa faktor ekonomi menjadi faktor yang paling berpengaruh bertahannya budaya sembur. Hal inilah yang menjadi salah satu faktor tidak langsung ketidakpatuhan pasien dalam melakukan pengobatan di fasilitas kesehatan. Berdasarkan hasil wawancara dengan petugas program TB Paru di Puskesmas Tarus, paling banyak pasien yang gagal minum obat selama 6 bulan karena pengaruh pengobatan sembur. Mereka meyakini pengobatan sembur lebih ampuh dibandingkan dengan pengobatan TB paru. Selain wawancara dengan petugas TB paru, peneliti juga mewawancarai bidan yang melakukan pemeriksaan pada ibu hamil menyatakan bahwa terdapat beberapa kasus malaria dalam kehamilan yang terdeteksi ketika mengalami malaria komplikasi seperti anemia dan perdarahan. Kondisi ini disebabkan ibu tidak pernah melakukan ANC saat posyandu dan datang ke PKM ketika akan melahirkan. Ini merupakan salah satu contoh perilaku masyarakat setempat yang tidak memperhatikan protokol pemeriksaan kehamilan.

\section{- Harapan terhadap kehidupan kedepan}

Hampir semua informan memiliki harapan yang besar terhadap budaya sembur, karena menurut mereka sembur mampu menenangkan perasaan bagi orang yang sakit, dapat diuraikan dalam uraian dari kategori - kategori sebagai berikut:

a. Memiliki Goal

Terdapat dua orang informan yang menyatakan tindakan sembur merupakan salah satu cara untuk menenangkan hati orang yang sakit, seperti yang dijelaskan dalam verbatim berikut:

"Son usah pikir yang macam-macam yang penting kakak dong selamat, lekas sembuh" (Wawancara CN; BK; RK; TRL).

\section{b. Pathway thinking}

Terdapat satu orang informan yang menyatakan tindakan sembur yang dilakukan selama ini perlu di kombinasikan dengan pengobatan herbal, seperti yang dijelaskan dalam verbatim berikut:

"Saya perlu belajar banyak dengan ahli yang berpengalaman dalam pengobatan herbal" (Wawancara NA).

Harapan yang dimiliki oleh informan menunjukan adanya harapan yang baik untuk keberlanjutan budaya ini namun perlu di kombinasikan dengan pengobatan herbal yang telah diakui manfaatnya. Kondisi inilah yang membutuhkan peran perawatan dengan pendekatan transcultural nursing teory. Teori tersebut berguna untuk memfasilitasi sistem perawatan yang dilakukan masyarakat awam dengan sistem perawatan prosfesional melalui asuhan keperawatan. Salah satu tindakan keperawatan yang diberikan kepada klien dengan memperhatikan prinsip Culture care preservation/maintenance, yaitu prinsip membantu, memfasilitasi, atau memperhatikan fenomena budaya guna membantu individu menentukan tingkan kesehatan dan gaya hidup yang di inginkan. 


\section{Kesimpulan}

Berdasarkan hasil penelitian dan uraian pembahasan dapat disimpulkan tentang bagaimana gambaran budaya sembur dalam perawatan ibu hamil penderita malaria. Analisa data secara induktif menghasilkan serangkaian gambaran tentang budaya sembur dalam perawatan ibu hamil penderita malaria.

Pertama, Pengambilan keputusan masyarakat dalam memilih budaya sembur di Kabupaten Kupang disebabkan oleh adanya kepercayaan dan praktek kesehatan yang telah dilakukan oleh leluhurnya ketika mencari pengobatan saat sakit. Selain itu pelaksanaan budaya sembur merupakan suatu pola keyakinan yang telah ditanamkan oleh orang tua secara turun temurun dari beberapa etnis yang ada di Pulau Timor ketika merawat orang sakit. Kedua, nilai-nilai yang diyakini ketika melakukan budaya sembur adalah merupakan wujud dari sikap patuh pada kebiasaan leluhur dengan tujuan membantu sesama manusia yang sakit tanpa pamrih. Ketiga, para informan memiliki harapan terhadap kehidupan kedepan yaitu harapan yang baik untuk keberlanjutan budaya ini namun perlu di kombinasikan dengan pengobatan herbal yang telah diakui manfaatnya.

\section{Referensi}

Ashley, E., McGready, R., Proux, S., \& Nosten, F. (2006). Malaria. Travel Medicine and Infectious Disease. https://doi.org/10.1016/j.tmaid.2005.06.009

Badan Penelitian dan Pengembangan Kesehatan Kementerian Kesehatan RI. (2013). RISKESDAS 2013. website: www.litbang.depkes.go.id\%0A

BPS Provinsi NTT. (2018). Jumlah Kasus Malaria Menurut Kabupaten/Kota di Provinsi Nusa Tenggara Timur, 2015-2018. https://ntt.bps.go.id/dynamictable/2018/08/31/764/jumlah-kasus-malariamenurut-kabupaten-kota-di-provinsi-nusa-tenggara-timur-2015-2017.html

Briand, V., Cottrell, G., Massougbodji, A., \& Cot, M. (2007). Intermittent preventive treatment for the prevention of malaria during pregnancy in high transmission areas. In Malaria Journal. https:/ / doi.org/10.1186/1475-2875-6-160

Doku, D. T., Zankawah, M. M., \& Adu-Gyamfi, A. B. (2016). Factors influencing dropout rate of intermittent preventive treatment of malaria during pregnancy. BMC Research Notes. https://doi.org/10.1186/s13104-016-2265-2

Dyah, A. . (2012). Pengalaman Ibu Hamil menderita malaria dalma merawat dirinya di Kabupaten Mimika Papua [Universitas Indonesia]. http:/ /lib.ui.ac.id/bo/uibo/ detail.jsp?id=20302559\&lokasi=lokal.

Foster, G., \& Anderson. (1986). Antropologi Kesehatan. UI Press.

Gaol, T. L. (2013). Pengaruh Faktor Sosiodemografi, Sosioekonomi dan Kebutuhan terhadap Perilaku Masyarakat dalam Pencarian Pengobatan di Kecamatan Medan Kota Tahun 2013. Tesis.

Geertz, C. (1981). Abangan, Santri, Priyayi dalam Masyarakat Jawa. Pustaka Jaya.

Ghana Health Service. (2009). Guidelines For Malaria In Pregnancy. http: //www.evidence.nhs.uk

Hawkins, P. (2012). Creating a coaching culture. Bell and Bain Ltd. https://www.academia.edu/7895334/CREATING_A_COACHING_CULTURE_ by_Peter_Hawkins.

Hoelman, M. ., Parhusip, B., Eko, S., Bahagijo, S., \& Santono. H. (2015). Panduan SDGs untuk pemerintah daerah (Kota dan Kabupaten). INFID. 
https:/ / batukarinfo.com/referensi/panduan-sdgs-untuk-pemerintah-daerahkota-dan-kabupaten-dan-pemangku-kepentingan-daerah

Kadir, Y.-. (2018). Dimensi Sosial Budaya Bagi Keragaman Praktik Perawatan Kesehatan Penderita Malaria di Topoyo Provinsi Sulawesi Barat. ETNOSIA : Jurnal Etnografi Indonesia. https:// doi.org/10.31947/etnosia.v3i2.4154

Kamus Besar Bahasa Indonesia. (n.d.). https://kbbi.web.id/

Kapitan, M. (2013). Effect healthy mother package on knowledge and bahaviour of overcoming clinical symptoms during malaria attack among pregnant women in Southwest Sumba. Proceeding International Nursing Conference $3 \mathrm{rd}$.

Kapitan, M., \& Ludji, I. (2019). Pengalaman ibu hamil penderita malaria komplikasi di RSU Soe Timor Tengah Selatan. Jurnal Penyakit Bersumber Binatang The Journal of Zoonozis, 6(2 Maret).

Koentjaraningrat. (2000). Pengantar Ilmu Antropologi. Rineka Cipta.

Leiningier, M. dan, \& McFarland, M. . (2002). Transcultural nursing: Concepts, theories, research and practice (Third). MC-Graw Hill Companies.

Okafor, I. ., Mbah, M., \& USANGA, E. . (2012). The Impact of Anaemia and Malaria Parasite Infection In Pregnant Women. Nigerian Perspective. IOSR Journal of Dental and Medical Sciences. https:/ / doi.org/10.9790/0853-0113438

Olorunfemi E Amoran, A, A. A., \& A, I. C. (2012). Determinants of intermittent preventive treatment of malaria during pregnancy (IPTp) utilization in a rural town in Western Nigeria. Reproductive Health, 9(12), 1-8. https://reproductive-healthjournal.biomedcentral.com/track/pdf/10.1186/1742-4755-9-12

Rosenstock, I. M. (1974). Historical origins of the health belief model. Health Education Monographs. Health Education Monographs. https:/ / doi.org/http:/ /dx.doi.org/10.1177/109019817400200403

Rospand, R. (2008). Pertimbangan budaya dalam pengkajian pasien. https:/ / docplayer.info/31221394-Pertimbangan-budaya-dalam-pengkajianpasien.html

Said M B. (1996). Dukun. Suatu Kajian Sosial Budaya tentang Fungsi Dukun Bugis Makassar di Kotamadya Ujung Pandang [Universitas Indonesia]. http:/ /lib.ui.ac.id/detail?id=80532\&lokasi=lokal

Schantz-Dunn, J., \& Nour, N. M. (2009). Malaria and pregnancy: a global health perspective. Reviews in Obstetrics \& Gynecology.

Soekanto, S. dan, \& Sulistyowati, B. (2012). Sosiologi Suatu Pengantar. Rajawali Pers. id.wikipedia.org/wiki/Budaya yourarticlelibrary.com/culture/culture-themeaning-characteristics-and-functions/9577

Soerachman, R dan Wiryawan, Y. (2013). Persepsi dan sikap masyarakat desa di Kabupaten Timor Tengah Selatan tentang melahirkan. Jurnal Kesehatan Reproduksi, 4(Nomor 1 April), 16-22.

Suparman, E., \& Suryawan, A. (2004). Malaria pada Kehamilan. In Jkm.

Tim Riskesdas 2018. (2019). RISKESDAS 2018 LAPORAN PROVINSI NTT. Badan Penerbit BALITBANGKES.

Unicef Kupang. (2016). Akselerasi menuju eliminasi malaria di provinsi Nusa Tenggara Timur.

YOUNG, J. C. (1980). a model of illness treatment decisions in a Tarascan town. American Ethnologist. https://doi.org/10.1525/ae.1980.7.1.02a00070 